\title{
Coating method for smooth and reinforced surface layer of highly translucent zirconia
}

\author{
Yoshiro FUJII', Masahiro OKADA¹, Hiroaki TAKETA² and Takuya MATSUMOTO1 \\ ${ }^{1}$ Department of Biomaterials, Graduate School of Medicine, Dentistry and Pharmaceutical Sciences, Okayama University, 2-5-1 Shikata-cho, Kita-ku, \\ Okayama 700-8558, Japan \\ ${ }^{2}$ Department of Comprehensive Dentistry, Okayama University Hospital, 2-5-1 Shikata-cho, Kita-ku, Okayama 700-8558, Japan \\ Corresponding author, Takuya MATSUMOTO; E-mail: tmatsu@md.okayama-u.ac.jp
}

\begin{abstract}
Due to the recent evolution of dental ceramic materials, highly translucent zirconia materials have been developed. While this material has high aesthetics, there is still room for improvement in strength. In this study, we investigated to strengthen the high translucent zirconia material. In the study, monoclinic zirconia $\left(\mathrm{mZrO}_{2}\right)$ nanoparticles were used as a coating agent. The surface of the highly transparent zirconia was coated with $\mathrm{mZrO}_{2}$ nanoparticle dispersion by dipping and sintered. Thereby, the high translucent zirconia could obtain about 1.3 times higher strength than the untreated one. The post-coating method introduced in this study would be effective as a simple and economical method for improving highly translucent zirconia strength.
\end{abstract}

Keywords: Highly translucent zirconia, Coating, $\mathrm{mZrO}_{2}$, Nanoparticle

\section{INTRODUCTION}

Due to their high aesthetics and high biocompatibility, ceramic restorations are in high demand in dentistry ${ }^{1,2}$. Among dental ceramics, zirconia has been paid attention as a metal-free restoration material due to its high strength. In recent years, partially stabilized zirconia (PSZ) whose crystal phase composition has been changed by increasing the $\mathrm{Y}_{2} \mathrm{O}_{3}$ content to $5 \mathrm{~mol} \%$ has been developed as highly translucent zirconia ${ }^{3,4)}$. PSZ contains a large amount of cubic zirconia $\left(\mathrm{cZrO}_{2}\right)$, and reduces the contents of tetragonal zirconia $\left(\mathrm{tZrO}_{2}\right)$, monoclinic zirconia $\left(\mathrm{mZrO}_{2}\right)$, and $\mathrm{Al}_{2} \mathrm{O}_{3}$, which cause light scattering. The translucency is improved, however, high translucent PSZ containing a large amount of $\mathrm{cZrO}_{2}$ has a problem that its mechanical strength is inferior due to the low ratio of stress-induced phase transition like conventional yttria-stabilized tetragonal zirconia polycrystal (Y-TZP) ${ }^{4}$. As a method for improving the mechanical strength of a highly translucent PSZ, adding metal oxides other than yttria has been reported so $\mathrm{far}^{5,6)}$. In addition, a method of penetrating glass into the zirconia surface has been reported for strengthening the materials ${ }^{7}$. However, the improvement of the mechanical strength of the highly translucent PSZ by these methods is still insufficient. Therefore, there is a demand for a method for simply and economically increasing the mechanical strength of the highly translucent PSZ.

We aim to develop a method to increase the mechanical strength of highly translucent PSZ. In a previous report, we constructed the surface compressive stress layer of tempered glass, and showed that a ceramic coating on the surface of zirconia forms a surface compressive stress layer to increase mechanical strength while maintaining high translucency ${ }^{8}$. A dispersion of two kinds of nanoparticles, $\mathrm{mZrO}_{2}$ and silica $\left(\mathrm{SiO}_{2}\right)$, was used as a coating material. The purpose of $\mathrm{mZrO}_{2}$ in the coating layer was to form a compressive stress layer on the PSZ surface, and $\mathrm{SiO}_{2}$ was added as an inorganic binder. In this method, island-like structures were formed on the coated surface, and the increase in surface irregularities was observed. That is, this method would be useful as a coating method for the inner surface of a dental prosthesis. However, when applied this to the aesthetic surface, there is a concern that plaque adhesion will increase $\mathrm{e}^{9)}$ and opposing teeth will wear due to the increase in the surface irregularities ${ }^{10)}$. Therefore, in this study, we aimed to form a smoother coating layer on aesthetic side of highly translucent PSZ substrate. Here, we report the successful formation of an ideal coating layer by heat treatment after adsorbing the $\mathrm{mZrO}_{2}$ nanoparticles uniformly.

\section{MATERIALS AND METHODS}

\section{Materials}

The highly translucent PSZ semi-sintered product (Katana UTML) was provided by Kuraray Noritake Dental (Tokyo, Japan). The crystal composition of Katana UTML is reported to be $70.6 \mathrm{wt} \%$ of $\mathrm{cZrO}_{2}, 28.9 \mathrm{wt} \%$ of $\mathrm{tZrO}_{2}, 0.2 \mathrm{wt} \%$ of $\mathrm{mZrO}_{2}$, and $0.3 \mathrm{wt} \%$ of rhombohedral zirconia $\left(\mathrm{rZrO}_{2}\right)^{4}$. The $\mathrm{mZrO}_{2}$ nanoparticles used as the coating material were synthesized by hydrothermal method of a $4 \mathrm{~mol} / \mathrm{L} \mathrm{ZrOCl}{ }_{2}$ (Wako Pure Chemical, Osaka, Japan) aqueous solution at $200^{\circ} \mathrm{C}$ for $100 \mathrm{~h}^{11}$. The obtained nanoparticles were washed by centrifugation, dried, and then dispersed in water (10 wt\%). The dispersed nanoparticles were dried on an aluminum tub for scanning electron microscope (SEM) observation. Polyacrylic acid (PAA, molecular weight 5000) (Wako Pure Chemical) was used as a binder. 


\section{Sample preparation}

1. Surface pretreatment

PSZ semi-sintered body was cut into a disk $(\phi=14$ $\mathrm{mm}$, thickness $1.2 \mathrm{~mm}$, Buehler low speed cut-off saw, Buehler, Uzwil, Switzerland), and fired at $1,550^{\circ} \mathrm{C}$ for $2 \mathrm{~h}$ (temperature increased from room temperature to $1,550^{\circ} \mathrm{C}$ at $10^{\circ} \mathrm{C} / \mathrm{min}$, at $10^{\circ} \mathrm{C} / \mathrm{min}$ or less to room temperature) (untreated group; Group AS) by using furnace (KBF314, Koyo Thermo Systems, Nara, Japan). After sintering, both sides of the disk were polished continuously using P1000, P2000, and P3000 silicon carbide polishing paper under tap water irrigation (Nippon Kenshi, Hiroshima, Japan) (polishing group; Group P). For polishing, one side of each disk was polished, and a new paper was used.

\section{Surface treatment}

Ten microliters of $1 \mathrm{wt} \%$ PAA aqueous solution was applied to the polished surface of the obtained sintered PSZ disk, washed, and dried. As a result, PAA was adsorbed on the sample surface. Thereafter, using a micropipette, $10 \mu \mathrm{L}$ of a $10 \mathrm{wt} \% \mathrm{mZrO}_{2}$ dispersion was applied, washed and dried for $10 \mathrm{~s}$ to adsorb $\mathrm{mZrO}_{2}$ nanoparticles. These PPA- $\mathrm{mZrO}_{2}$ coatings were repeated at most 5 times.

\section{Heat treatment}

The sample coated with $\mathrm{mZrO}_{2}$ was heated in a firing furnace (KBF314; Koyo Thermo Systems) at $1,550^{\circ} \mathrm{C}$ for $2 \mathrm{~h}$ (heating from room temperature to $1,550^{\circ} \mathrm{C}$ at $10^{\circ} \mathrm{C} / \mathrm{min}, 10^{\circ} \mathrm{C} / \mathrm{min}$ or less to room temperature (Group $\mathrm{P}-\mathrm{mZrO}_{2}-\mathrm{T}$ ). The coating procedure used in this study is summarized in Fig. 1. The polished sample without $\mathrm{mZrO}_{2}$ coating was also heated under the same conditions (Group P-T) to investigate the influence of $\mathrm{mZrO}_{2}$ coating.

\section{Measurement of mechanical strength}

As a mechanical strength test, a biaxial bending test of the sample was performed using a universal testing
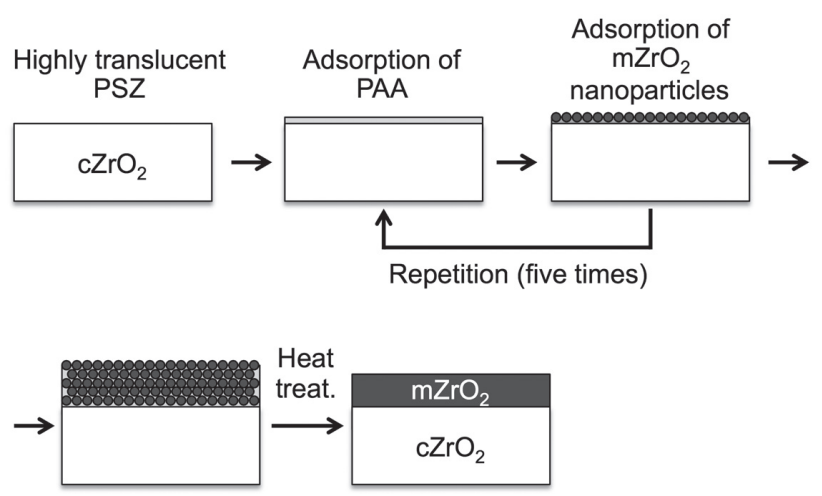

Fig. 1 A flow chart of $\mathrm{mZrO}_{2}$ coating on high translucent PSZ substrate.

PSZ, partially stabilized zirconia; $\mathrm{cZrO}_{2}$, cubic zirconia; $\mathrm{mZrO}_{2}$, monoclinic zirconia machine (Autograph AG-X; Shimadzu, Kyoto, Japan) $(n=5)$. Three stainless steel balls with a diameter of 3.2 $\mathrm{mm}$ are arranged at equal intervals in a concentric circle with a diameter of $10 \mathrm{~mm}$, the center of the disk and the three spheres are aligned, and the coated surface is on the side with the sphere, so that tensile stress is applied to the treated surface. A load was applied from the uncoated surface at a crosshead speed of $1.0 \mathrm{~mm} /$ min using an indenter having a diameter of $1.2 \mathrm{~mm}$ to generate a tensile stress on the coated surface. The biaxial bending strength was calculated from the breaking load of each sample using the following formula ${ }^{12}$.

$$
S=\frac{-0.2387 P(X-Y)}{d^{2}}
$$

Here, $S$ indicates the biaxial bending strength (MPa), $P$ indicates the breaking load $(\mathrm{N}), d$ indicates the thickness $(\mathrm{mm})$ of the sample disk, and $X$ and $Y$ were determined as follows.

$$
\begin{aligned}
& X=(1+v) \ln \left(\frac{r_{2}}{r_{3}}\right)^{2}+\left[\frac{1-v}{2}\right]\left(\frac{r_{2}}{r_{3}}\right)^{2} \\
& Y=(1+v)\left[1+\ln \left(\frac{r_{1}}{r_{3}}\right)^{2}\right]+(1-v)\left(\frac{r_{1}}{r_{3}}\right)^{2}
\end{aligned}
$$

Here, $v$ is the Poisson's ratio (0.25), $r_{1}$ is the radius of the support circle, $r_{2}$ is the radius of the load indenter, and $r_{3}$ is the radius of the sample.

\section{Surface observation and analysis}

The surface morphology of the sample was observed at an accelerating voltage of $5 \mathrm{kV}$ using a scanning electron microscope after the osmium coating (SEM: JSM-6701F; JEOL, Tokyo, Japan). The SEM images were taken at a representative place near the center of the sample.

The surface roughness profiles and average surface roughness $(R a)$ of each sample was recorded using a profilometer (HandySurf E-35B; Mitsutoyo, Kanagawa, Japan) with active tip radius of $2 \mu \mathrm{m}$, reading length of 2.0 $\mathrm{mm}$, and reading speed of $0.6 \mathrm{~mm} / \mathrm{s}$. Five measurements at different locations were recorded for each specimen, and the values were averaged.

The crystal phase on the sample surface was examined by X-ray diffraction (XRD) analysis. (RINT 2500HF; Rigaku, Tokyo, Japan) (Cu-Ka (1.54 A) at 40 $\mathrm{kV}, 200 \mathrm{~mA}$, scan speed $2 \% \mathrm{~min}$ ).

\section{Measurement of translucency}

The translucency of the treated sample was compared to an untreated control sample $(n=5)$. The spectral reflectance of the sample on a white $\left(L^{*}=96.7, a^{*}=-0.1\right.$ and $\left.b^{*}=-0.3\right)$ or black $\left(L^{*}=1.2, a^{*}=-0.3\right.$ and $\left.b^{*}=-0.1\right)$ ceramic tile background was measured using a spectrophotometer (CM-3600d, Konica Minolta, Tokyo, Japan). A hydrocarbon oil (pentadecane; refractive index $n_{\mathrm{D}}=1.43$ ) was used to contact the sample surface with the background. The value of the translucency parameter (TP) was calculated by the difference between the color components of the same sample on black and white 
background according to the following equation ${ }^{12,13)}$.

$$
\mathrm{TP}=\left[\left(L_{B}^{*}-L_{W}^{*}\right)^{2}+\left(a_{B}^{*}-a_{W}^{*}\right)^{2}+\left(b_{B}^{*}-b_{W}^{*}\right)^{2}\right]^{2}
$$

Here, $L^{*}, a^{*}$, and $b^{*}$ are lightness, green-red, and blueyellow components, respectively. Subscripts $B$ and $W$ refer to the color components on a black and white background, respectively.

\section{Vickers hardness measurement}

Vickers hardness $\left(\mathrm{H}_{\mathrm{V}}\right)$ was measured at 1,000 gf for 15 s using a micro hardness tester (FM-700, Future-Tech, Kanagawa, Japan). Measurements were taken at five individual points on each sample.

\section{Statistical analysis}

The Steel-Dwass test was performed to detect multiple comparisons of $R a$ among the four experimental groups. After testing the normality and uniformity of the variance using the Shapiro-Wilk and Levene tests, respectively, followed by the Tukey-Kramer test to make multiple comparisons of biaxial bending strength or $\mathrm{Hv}$ values among the four experimental groups. All statistical analysis was performed using $\mathrm{R}$ statistical software (version 3.3.2; R Foundation for Statistical Computing, Vienna, Austria). The significance level was 0.05.

\section{RESULTS}

\section{Coating material}

Figure 2 shows a SEM image and a XRD pattern of $\mathrm{mZrO}_{2}$ nanoparticles synthesized by the hydrothermal treatment method. The nanoparticles had a particle size of $20-50 \mathrm{~nm}$. The XRD pattern showed a monoclinic phase of crystals with a broad peak. As a result of firing the nanoparticle solely at $1,550^{\circ} \mathrm{C}$, each peak was sharpened while maintaining the monoclinic structure.

\section{Optimization of number of coatings}

In order to optimize the number of $\mathrm{mZrO}_{2}$ coatings, SEM observations were performed with the number of
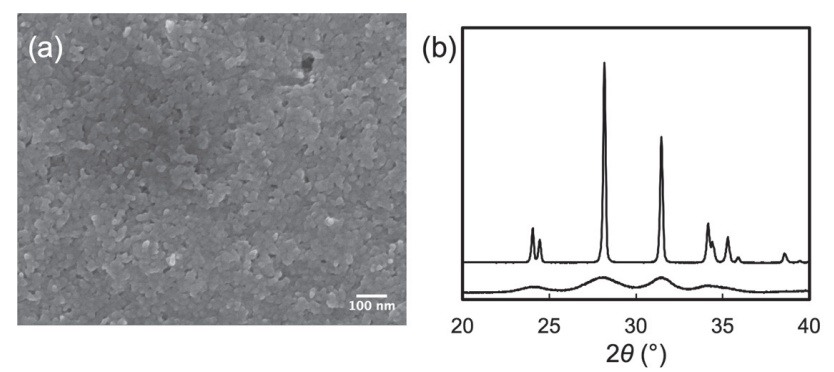

Fig. 2 (a) SEM photograph and (b) XRD pattern of $\mathrm{mZrO}_{2}$ nanoparticles prepared by hydrothermal treatment at $200^{\circ} \mathrm{C}$.

The XRD pattern was also measured after heat treatments at $1,550^{\circ} \mathrm{C}$ (heating rate, $10^{\circ} \mathrm{C} / \mathrm{min}$ ) for $2 \mathrm{~h}$. coatings varied. Figure 3 shows SEM images of sample surface before and after coating once and five times, respectively. Note that as-sintered disks were used to observe the coating layer (or base surface) clearly and heating was not performed after coating in this observation. Micron-size crystal grains are observed on the PSZ surface before coating. In the sample coated once, uncoated region was observed near the grain boundary. Increasing the number of coatings reduced the percentage of uncoated areas, resulting in a uniform
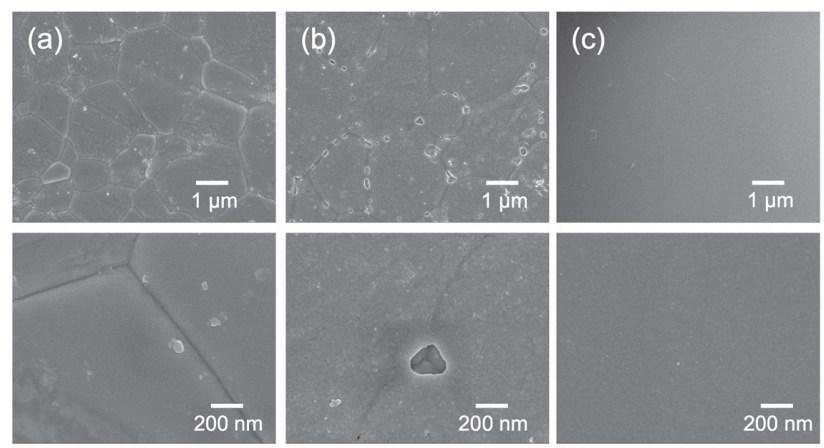

Fig. 3 SEM photographs of (a) as-sintered PSZ and (b, c) those after coating PAA and $\mathrm{mZrO}_{2}$ nanoparticles (b) 1 time and (c) 5 times.
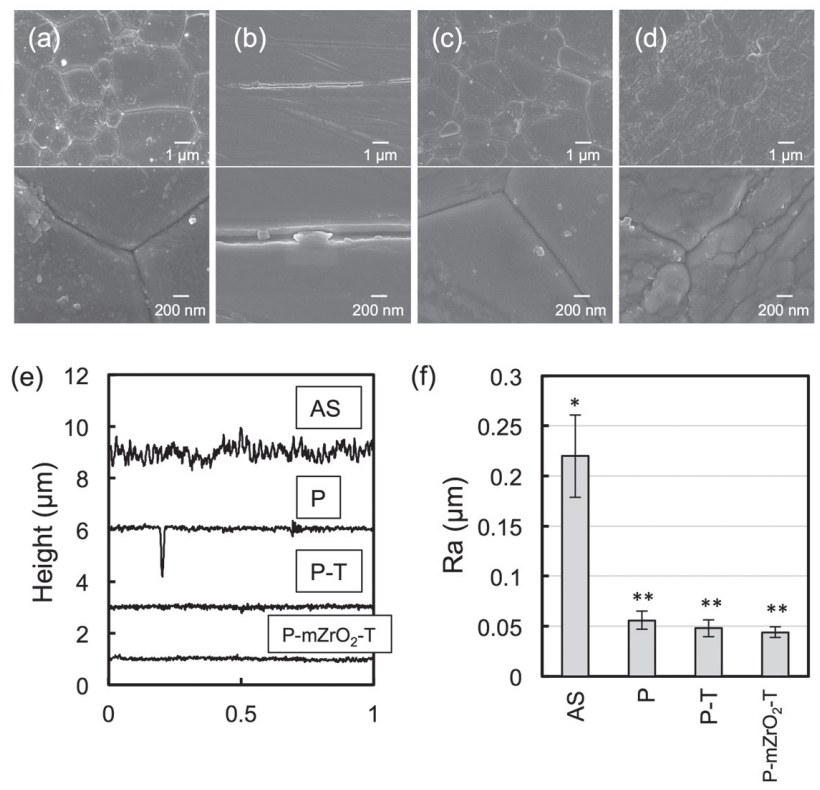

Fig. 4 SEM photographs of (a) as-sintered (AS), (b) polished (P), (c) polished/heated (P-T) and (d) polished $/ \mathrm{mZrO}_{2} /$ heated $\mathrm{PSZ}$ samples $\left(\mathrm{P}-\mathrm{mZrO}_{2}-\mathrm{T}\right)$. The photographs in the upper were taken at $\times 10,000$ magnifications, and those in the lower were taken at $\times 50,000$ magnifications. (e) Surface roughness profiles and (f) $R a$ values of each samples. Asterisks $(*)$ in the graph (f) indicate statistically significant difference from Steel-Dwass test $(p<0.05 ; n=5)$. 

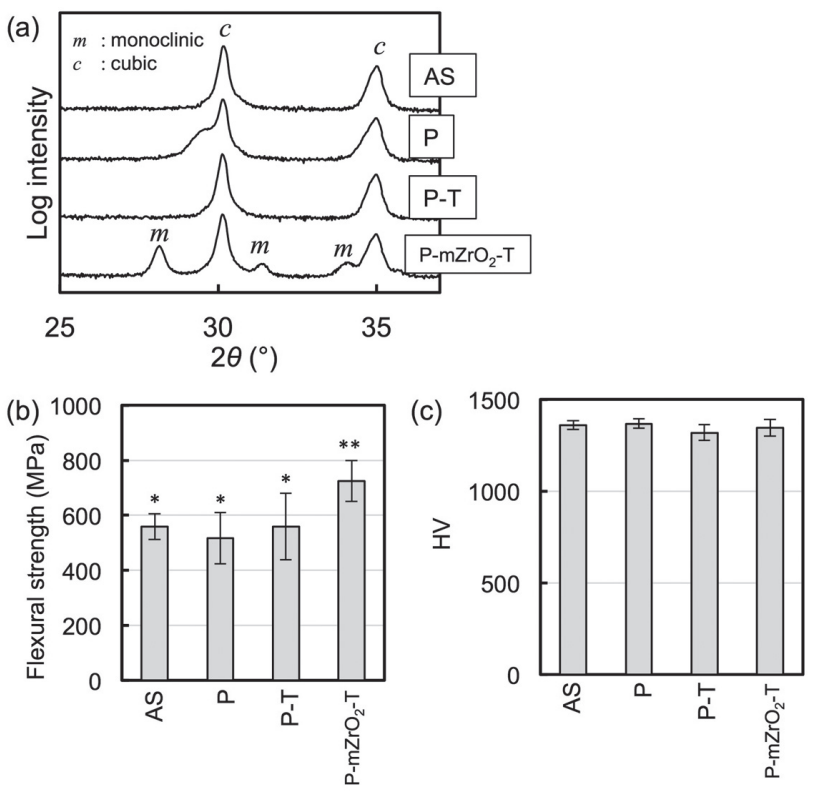

Fig. 5 (a) XRD patterns of as-sintered, polished (P), polished/heated (P-T) and polished $/ \mathrm{mZrO}_{2} /$ heated PSZ samples (P-mZrO $2-\mathrm{T})$. (b) Biaxial flexural strengths of samples. Different symbols on the bars indicate statistically significant difference from Tukey-Kramer tests ( $p<0.05 ; n=5)$. (c) Vicker's hardness (HV) values of samples. ANOVA analysis indicates that there is no statistically effect ( $p>0.05$; $n=5)$.

coating with five coatings.

\section{Surface morphology}

Figure $4 \mathrm{a}-\mathrm{d}$ shows SEM images of Groups P, P-T, and $\mathrm{P}-\mathrm{mZrO}_{2}$-T. In Group P, the crystal grains seen in Group AS were not observed. In Group P-T, recrystallization by thermal annealing was observed. In Group P- $\mathrm{mZrO}_{2}$ - $\mathrm{T}$, submicron order crystal grains were observed due to the sintering of $\mathrm{mZrO}_{2}$ nanoparticles and adhesion to the base material.

\section{Surface roughness}

Figure $4 \mathrm{e}$ and $\mathrm{f}$ show the results of surface roughness and $R a$ values. From the surface roughness profile, Group $\mathrm{P}$ had a micron-order concave part, which is considered to be due to polishing marks seen in the SEM images. Such large recesses were not observed in Group P-T and Group P- $\mathrm{mZrO}_{2}$-T. Group AS showed the largest $R a$ value, and no significant difference was observed within the other groups.

\section{XRD analysis}

Figure 5 a shows the XRD pattern. The vertical axis is shown on a log scale to highlight small peaks. Group AS showed single phase of $\mathrm{cZrO}_{2}$. The formation of rhombohedral crystals was confirmed in Group P, but disappeared by heat treatment (Group P-T). In Group (a)

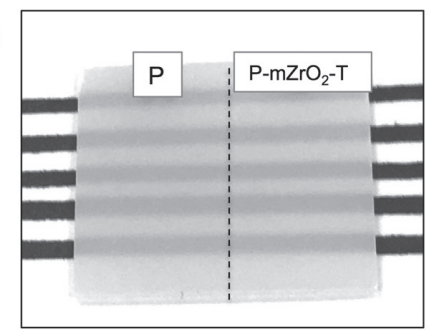

(b)

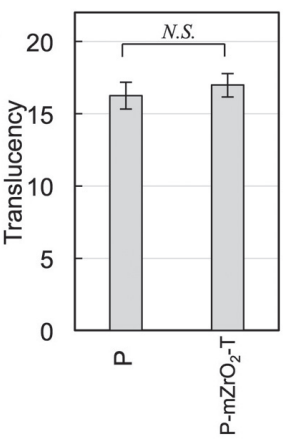

Fig. 6 (a) Digital image of the PSZ substrate, of which the left half was not coated $(\mathrm{P})$ and the right half was coated with $\mathrm{mZrO}_{2}$ at $1,550^{\circ} \mathrm{C}\left(\mathrm{P}-\mathrm{mZrO}_{2}-\mathrm{T}\right)$, showing the similar translucency after $\mathrm{mZrO}_{2}$ coating. (b) Translucency parameters of samples. N.S. (no statistical difference) by Welch's test $(p>0.05 ; n=5)$.

$\mathrm{P}-\mathrm{mZrO}_{2}-\mathrm{T}$, monoclinic crystals were detected in addition to cubic crystals.

\section{Biaxial bending strength}

Figure $5 \mathrm{~b}$ summarizes the biaxial bending strength. No significant difference was observed among Group AS, Group P, and Group P-T. The biaxial bending strength was approximately $550 \mathrm{MPa}$. On the other hand, the biaxial bending strength of Group P- $\mathrm{mZrO}_{2}$-T increased significantly to $724.8 \mathrm{MPa}$.

\section{Vickers hardness}

Figure $5 \mathrm{c}$ shows the results of Vickers hardness. No significant difference was observed among the groups.

\section{Translucency of sample after surface treatment}

As a result of comparing the light transmittance of Group P and Group P-mZrO ${ }_{2}$-T (Fig. 6), no significant difference was observed between the two groups.

\section{DISCUSSION}

In this study, $\mathrm{mZrO}_{2}$ nanoparticles were used as the main component of the coating material to form a smooth and reinforced coating layer. By applying heat treatment after applying $\mathrm{mZrO}_{2}$ dispersion multiple times, the biaxial bending strength was successfully improved without increasing the surface roughness and without lowering the light transmittance, which would be due to the thin thickness of the coating layer. Assuming that the calculation method for monoclinic phase thickness ${ }^{14)}$, which is well established to estimate the depth of stressinduced $\mathrm{mZrO}_{2}$ transformation of tetragonal-stabilized zirconia polycrystals (TZP) and relates with the zirconia strength $^{15)}$, could be also applicable in this case, the $\mathrm{mZrO}_{2}$ coating thickness was calculated to be $0.20 \mu \mathrm{m}$.

One of the strengthening mechanisms of $\mathrm{mZrO}_{2}$ coating would be the formation of compressive stress 
due to thermally-induced crystal phase transformation: The $\mathrm{mZrO}_{2}$ (density, $5.83 \mathrm{~g} / \mathrm{cm}^{3}$ ) is thermodynamically stable at room temperature, undergoes transformation to tetragonal phase $\left(\mathrm{tZrO}_{2}\right.$; density, $\left.6.1 \mathrm{~g} / \mathrm{cm}^{3}\right)$ at high temperature and undergoes reverse transformation to monoclinic phase with volume expansion ( $c a .4 \%$ ) upon cooling ${ }^{16}$. The actual monoclinic-tetragonal phase transformation exhibits hysteresis, and the transformation temperature upon heating and cooling have been reported to be approximately 1,227 and $927^{\circ} \mathrm{C}$, respectively ${ }^{17,18)}$. Therefore, thermal annealing of the $\mathrm{mZrO}_{2}$ coated samples above $1,227^{\circ} \mathrm{C}$ is expected to induce compressive stress by preventing the volume expansion upon cooling at approximately $927^{\circ} \mathrm{C}$. Of note, the compressive stress would also be formed during the cooling process after annealing due to the smaller thermal expansion coefficient of the $\mathrm{mZrO}_{2}$ coating layer (approximately $6 \times 10^{-6} \mathrm{~K}^{-1}{ }^{19}$ ) ) compared to that of the $\mathrm{cZrO}_{2}$ substrate $\left(8.5 \times 10^{-6} \mathrm{~K}^{-120)}\right)$. Assuming that the $\mathrm{mZrO}_{2}$ coating layer was forced to be shrunk uniformly during the cooling process from $927^{\circ} \mathrm{C}$ to room temperature accompanied by the $\mathrm{cZrO}_{2}$ shrinkage, the compressive strain in the coating layer was calculated to be $0.22 \%$.

In the previous report, $\mathrm{SiO}_{2}$ was used as a binder to prevent cracks in the coating layer ${ }^{8}$. However, it was unsuitable for the outer surface of the dental prosthesis because the surface became rough. This time, in order to prevent crack formation, we reduced the amount of coating at one time, added an organic binder between coating layers.

The idea of using nano-sized $\mathrm{ZrO}_{2}$ for surface coatings has already been reported. For example, Venkatesh et al. reported that nano-sized $\mathrm{ZrO}_{2}$ was added to the glazing material of zirconia restorations ${ }^{21}$. However, the actual crystalline phase of nano-sized $\mathrm{ZrO}_{2}$ used in the study was unknown, and its content was small (13.4 wt\% maximum). Therefore, in this study, by using only $\mathrm{mZrO}_{2}$, we achieved to obtain the 1.3 times higher biaxial bending strength without the change of translucency compared to those of the untreated sample.

Recently, it is commonly known that yttria-based zirconia has a natural tooth tone and excellent light transmission ${ }^{21)}$. Also, previous report indicated that the ceria-based nano-zirconia has more than twice the fracture toughness (single edge pre-cracked beam method) and bending strength compared to yttriabased zirconia $^{22)}$. Research has been conducted to obtain ceramics showing both high translucency and high mechanical strength by mixing these two types of zirconia ${ }^{23)}$. However, the results showed that while increasing the strength of zirconia, its translucency decreases. Using our method, we succeeded in increasing the bending strength more than 1.3 times without changing the translucency. However, this method requires the coating material applications for five times. Therefore, there is a need for further simplification. Other approaches, such as immersion in the $\mathrm{mZrO}_{2}$ nanoparticle dispersion, may eliminate this complication. Addition of appropriate amounts of ceria-based zirconia and/or alumina particles to $\mathrm{mZrO}_{2}$ nanoparticles may lead to further improvements in stability. These are issues for the future. Also, our method increased the strength up to $720 \mathrm{MPa}$. However, the actual highly translucent PSZ has a strength of $1,200 \mathrm{MPa}$, and another method must be proposed to reproduce this.

\section{CONCLUSION}

An acrylic acid aqueous solution binder was applied to the surface of the highly translucent PSZ, and then the $\mathrm{mZrO}_{2}$ nanoparticle dispersion was applied several times and heat-treated at $1,550^{\circ} \mathrm{C}$. As a result, the mechanical strength was successfully improved while maintaining the translucency of the highly translucent PSZ. This coating would be an effective method for expanding the usage of highly translucent PSZ.

\section{CONFLICTS OF INTEREST}

The authors declare no conflicts of interests associated with this manuscript.

\section{REFERENCES}

1) Öland W, Schweiger M, Watzke R, Peschke A, Kappert A. Ceramics as biomaterials for dental restoration Expert Rev Med Device 2008; 5: 729-745.

2) Zhang Y, Kelly JR. Ceramics for restoration and metal veneering. Dent Clin North Am 2017; 61: 797-819.

3) Mao L, Kaizer MR, Zhao M, Guo B, Song YF, Zhang Y. Graded ultra-translucent zirconia for strength and functionalities. J Dent Res 2018; 97: 1222-1228.

4) Inokoshi M, Shimizu H, Nozaki K, Takagaki T, Yoshihara $\mathrm{K}$, Nagaoka N, et al. Crystallographic and morphological analysis of sandblasted highly translucent dental zirconia. Dent Mater 2018; 34: 508-518.

5) Pozzobon JL, Pereira GKR, Wandscher VF, Dorneles LS, Valandro LF. Mechanical behavior of yttria-stabilized tetragonal zirconia polycrystalline ceramic after different zirconia surface treatments. Mater Sci Eng C Mater Biol Appl 2017; 77: 828-835.

6) Okada M, Taketa H, Torii Y, Irie M, Matsumoto T. Optimal sandblasting conditions for conventional-type yttriastabilizedtetragonal zirconia polycrystals. Dent Mater 2019; 35: 169-175.

7) Nguyen TPT, Oh GJ, Lim HP, Yun KD, Kim JW, Vu VT, et al. Evaluation of sandblasting on mechanical properties and cell response of bioactive glass infiltrated zirconia. J Nanosci Nanotechnol 2017; 17: 2740-2742.

8) Uno S, Okada M, Taketa H, Torii Y, Matsumoto T. Toughening of highly translucent zirconia by monoclinic $\mathrm{ZrO}_{2}$ and $\mathrm{SiO}_{2}$ particle coating. Dent Mater J 2020; 38: 295-301.

9) Rashid $H$. The effect of surface roughness on ceramics used in dentistry. Eur J Dent 2014; 8: 571-579.

10) Ghazal M, Kern M. The influence of antagonistic surface roughness on the wear of human enamel and nanofilled composite resin artificial teeth. J Prosthet Dent 2009; 101: 342-349.

11) Okada M, Taketa H, Hara ES, Torii Y, Irie M, Matsumoto T. Improvement of mechanical properties of Y-TZP by thermal annealing with monoclinic zirconia nanoparticle coating. Dent Mater 2019; 35: 970-978.

12) Wille S, Zumstrull P, Kaidas V, Jessen LK, Kern M. Low temperature degradation of single layers of multilayered zirconia in comparison to conventional unshaded zirconia: 
Phase transformation and flexural strength. J Mech Behav Biomed Mater 2018; 77: 171-175.

13) Pecho OE, Ghinea R, Ionescu AM, Cardona Jde L, Paravina RD, Pérez Mdel M. Color and translucency of zirconia ceramics, human dentine and bovine dentine. J Dent 2012; 40: e34-40.

14) Johnston WM, Ma T, Kienle BH. Translucency parameter of colorants for maxillofacial prostheses. Int J Prosthodont 1995; 8: 79-86.

15) Kurtulmus-Yilmaz S, Aktore H. Effect of the application of surface treatments before and after sintering on the flexural strength, phase transformation and surface topography of zirconia. J Dent 2018; 72: 29-38.

16) Kosmać T, Oblak C, Jevnikar P, Funduk N, Marion L. The effect of surface grinding and sandblasting on flexural strength and reliability of Y-TZP zirconia ceramic. Dent Mater 1999; 15: 426-433.

17) Kuwabara A, Tohei T, Yamamoto T, Tanaka I. Ab initio lattice dynamics and phase transformations of $\mathrm{ZrO}_{2}$. Phys Rev B 2005; 71: 064301.
18) Abi CB, Emrullahoǵlu OF, Said G. Microstructre and mechanical properties of $\mathrm{MgO}$-stabilized $\mathrm{ZrO}_{2}-\mathrm{Al}_{2} \mathrm{O}_{3}$ dental composites. J Mech Behav Biomed Mater 2013; 18: 123-131.

19) Subbarao EC, Maiti HS, Srivastava KK. Martensitic transformation in zirconia. Phys Stat Sol 1974; 21: 9-40.

20) Promakhov V, Kulkov N. Thermal expansion of oxide systems on the basis of $\mathrm{ZrO}_{2}$. J Silic Based Compos Mater 2014; 66: 81-83.

21) Venkatesh G, Thenmuhil D, Vidyavathy SM, Vinothan R. Effect of addition of nano zirconia in ceramic glazes. Adv Mater Res 2014; 984: 488-494.

22) Zhang F, Vanmeensel K, Batuk M, Hadermann J, Inokoshi M, Van Meerbeek B, et al. Highly-translucent, strong and aging-resistant 3Y-TZP ceramics for dental restoration by grain boundary segregation. Acta Biomater 2015; 16: 215222 .

23) Benzaid R, Chevalier J, Saâdaoui M, Fantozzi G, Nawa M, Diaz LA, et al. Fracture toughness, strength and slow crack growth in a ceria stabilized zirconia-alumina nanocomposite for medical applications. Biomaterials 2008; 29: 3636-3641. 